\title{
Acute appendicitis diagnosed with high-resolution endoscopy plus narrow-band imaging
}

Colonoscopic diagnosis of asymptomatic acute appendicitis is extremely rare. Acute appendicitis has been described as a complication of colonoscopy [1]; however, obstruction of the appendiceal lumen, with various causes, is believed to be the event that leads to the development of acute appendicitis.

We describe here the case of a 65-year-old woman who was referred to our endoscopy suite for colonoscopic evaluation of a right abdominal mass suspicious for colon cancer. She had no history of abdominal pain, fever, chills, night sweats, nausea, vomiting, or constipation. The colonoscopic examination was carried out with an Evis Exera II scope (Olympus CFQ180A). At colonoscopy, the appendix was found to be bulging into the cecum, with pus flowing from the orifice (Figures $\mathbf{1} \mathbf{a}-\mathbf{c}$ ). Probing with a biopsy forceps resulted in the release of more pus (Figure 1d). The patient underwent surgery, and the diagnosis of acute appendicitis was confirmed.

A case of asymptomatic early acute appendicitis initiated and diagnosed during colonoscopy has been described [2]. The present case is consistent with the view proposed by some authors $[3,4]$ that individuals with acute appendicitis may not have any symptoms if the pus drains into the cecum and they do not develop serositis. So far as we are aware, this is the first report in which acute appendicitis has been diagnosed with high-resolution endoscopy plus narrow-band imaging.

Endoscopy_UCTN_Code_CCL_1AD_2AJ
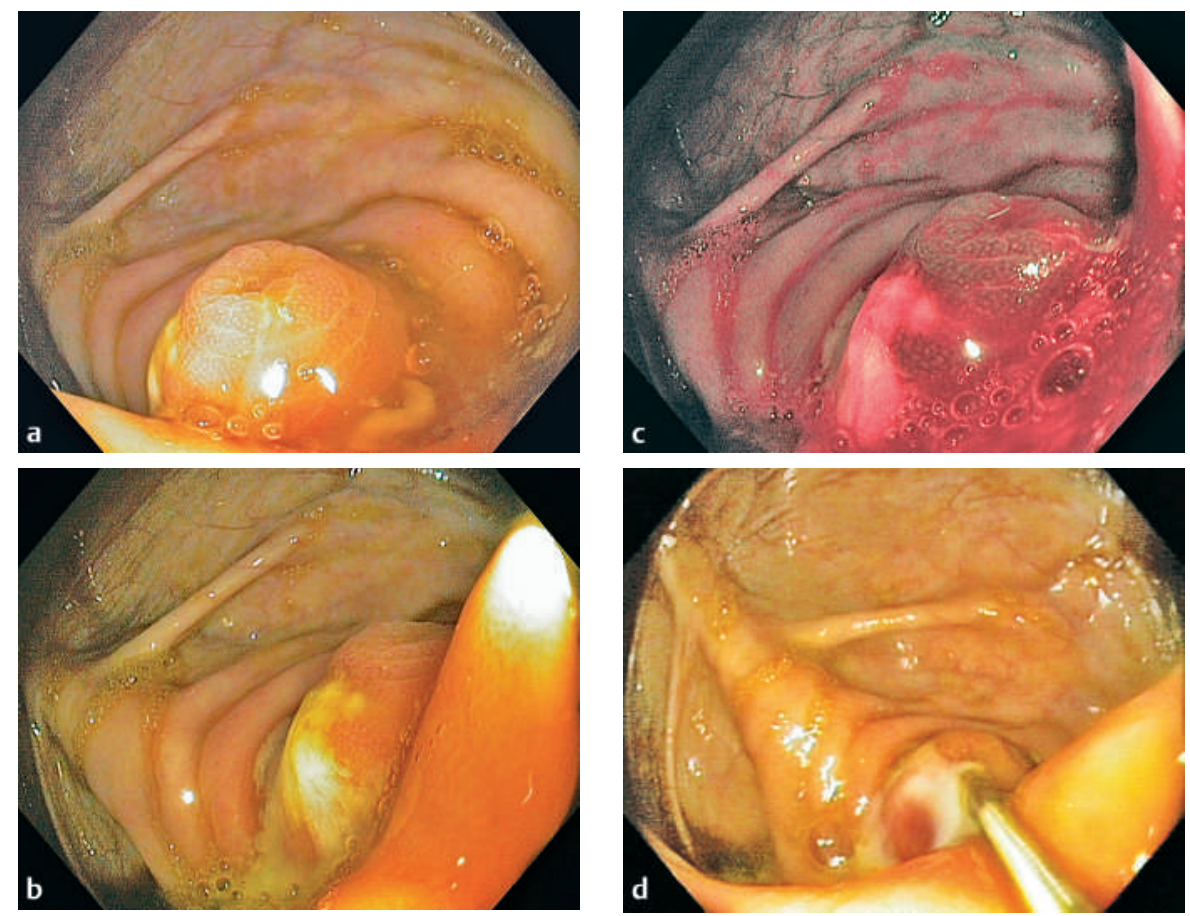

Figure 1 a Colonoscopy revealed a mildly erythematous and markedly edematous appendiceal orifice, with the appendix bulging into the cecal lumen and pus draining into the cecum. b, c The pus is flowing intraluminally into the cecum, as seen on high-resolution white-light imaging (b) and the corresponding narrow-band image (c). $\mathbf{d}$ Probing with a biopsy forceps resulted in the release of more pus.

\section{J. Boix, V. Lorenzo-Zúñiga,}

V. Moreno de Vega, M. A. Gassull

Endoscopy Unit, Dept. of

Gastroenterology, Germans Trias i Pujol

University Hospital, Badalona, Barcelona,

Spain.

\section{References}

${ }^{1}$ Vener R, Larson J, García J et al. Appendicitis as a complication of colonoscopy. Gastrointest Endosc 1995; 41: 514-516

2 Petro M, Minocha A. Asymptomatic early acute appendicitis initiated and diagnosed during colonoscopy: a case report. World J Gastroenterol 2005; 11: 5398-5400

3 Triadafilopoulos G. Acute appendicitis. Gastrointest Endosc 2001; 54: 624

${ }^{4}$ Kaushik N, Krasinkas A, Slivka A, McGrath K. Acute appendicitis. Gastrointest Endosc 2004; 60: $102-103$

\section{Corresponding author}

\section{J. Boix Valverde, M.D.}

Endoscopy Unit,

Dept. of Gastroenterology

Hospital Universitario Germans Trias i

Pujol

Carretera del Canyet s/n

08916 Badalona

Barcelona

Spain

Fax: $\quad+34-93-4978946$

E-mail: jboix@ns.hugtip.scs.es 